\title{
Trauma admissions among street children at a tertiary care hospital in north-western Tanzania: a neglected public health problem
}

\author{
PHILLIPO L. CHALYA ${ }^{1 *}$, KIYETI A. HAULI ${ }^{2}$, NEEMA M. KAYANGE 3 , WEMAELI MWETENI ${ }^{4}$, ANTHONY \\ KAPESSA 5 and SOSPATRO E. NGALLABA ${ }^{5}$ \\ 'Department of Surgery, Catholic University of Health and Allied Sciences-Bugando, Mwanza, Tanzania \\ ${ }^{2}$ Department of Psychiatry, Catholic University of Health and Allied Sciences-Bugando, Mwanza, Tanzania \\ ${ }^{3}$ Department of Paediatrics, Catholic University of Health and Allied Sciences-Bugando, Mwanza, Tanzania \\ ${ }^{4}$ Department of Community Medicine, Bugando Medical Centre, Mwanza, Tanzania \\ 5 Institute of Public Health, Catholic University of Health and Allied Sciences-Bugando, Mwanza, Tanzania
}

\begin{abstract}
:
Background: Trauma among street children is an emerging but neglected public health problem in most low and middle income countries. This study was conducted to determine the incidence, etiological spectrum, injury characteristics and treatment outcome among street children and to identify the predictors of the outcome of these patients at Bugando Medical Centre in Mwanza, Tanzania.

Methods: The study included street children aged $<18$ years. Routine investigations including haematological, biochemical and imaging were performed on admission. The severity of injury was determined using the Kampala Trauma Score II. Data on patient's characteristics, circumstances of injury, injury characteristics, treatment offered, outcome variables, length of hospital stay and mortality were collected using a questionnaire.

Results: A total of 342 street children (M: $F=6.8: 1)$ representing $11.5 \%$ of all paediatric injury patients were studied. The modal age group was 11-15 years (median $=12$ years) accounting for $53.2 \%(n=182)$ of the patients. Assault was the most frequent $(73.7 \%)$ cause of injury. More than three quarter of injuries occurred along the street. Most of patients $(59.1 \%)$ presented late (>24 hours) after injury. Blunt injuries were the most common (76.0\%) mechanism of injuries. Musculoskeletal (30.8\%) and head (25.3\%) were the most frequent body regions affected. Soft tissue injuries were the most common type of injuries affecting $322(94.2 \%)$ cases. Majority of patients (96.5\%) underwent surgical treatment of which wound debridement (97.6\%) was the most common surgical procedure performed. Complication rate was 39.5\%. The median hospital stay was 6 days. Mortality rate was $13.5 \%$ and it was significantly associated with injury-arrival time $(\mathrm{OR}=2.4,95 \% \mathrm{Cl}(1.3-5.6), \mathrm{p}=0.002)$, severe injury (Kampala Trauma Score $<6)(\mathrm{OR}=3.6,95 \% \mathrm{Cl}(2.5-7.9), \mathrm{p}=$ $0.001)$, severe head injuries $(\mathrm{OR}=5.1,95 \% \mathrm{Cl}(4.6-8.2), \mathrm{p}=0.012)$ and surgical site infection.

Conclusion: Trauma among street children is an emerging but neglected epidemic in Tanzania and contributes significantly to high morbidity and mortality. Assault was the most frequent cause of injury. Urgent preventive measures targeting at reducing the occurrence of assault is necessary to reduce the incidence of trauma among street children in this region.
\end{abstract}

Keywords: Street children, trauma, incidence, aetiological spectrum, injury characteristics, treatment outcome, Tanzania

\section{Introduction}

Street children, defined as those children under the age of 18 years who spend most of their lives on the street, have become a global phenomenon and concern (Ensign \& Gittelsohn, 1998). It is a problem of both developed and developing countries, but is more prevalent in the poor nations of Latin America, Asia and Africa (Aptekar, 1994; Mufune, 2000; Sorsa et al., 2002). Unprecedented global industrialization, urbanization, poverty, family disintegration due to health or death, neglect, abuse or abandonment, and social unrest are all common triggers for a child's life on the streets (Omiyinka \& Festus, 2010). The 'street children' phenomenon is a global concern whereby 150 million children around the world are living and/ or working on the streets

${ }^{*}$ Correspondence E-mail: drphillipoleo@yahoo.com 
(WHO, 2010; UNICEF., 2012). In Sub-Saharan Africa, the number of street children has been increasing due to the growing of AIDS orphans (Omiyinka \& Festus, 2010). Other factors such as marriage breakdown and divorce, young parenting and domestic violence are all contributors to the increase in the number of street children (Sorsa et al., 2002; Omiyinka \& Festus., 2010). In Tanzania, there are an estimated 437,500 street children many of whom live on the street because of the violence and abuse they suffer at home and many more face daily abuse on the streets from the police, sex tourists and even each other (Kopoka, 2000; Lugalla \& Mbwambo, 1999).

Various categories of street children exist. There are those who work on the streets as their only means of getting money, those who live on the street during the day but return to some form of family at night and those who permanently live on the street without a family network. All are at risk from abuse, exploitation and vigilante or police violence, but the most vulnerable are those who actually sleep and live on the streets, hiding under bridges, in gutters, in railway stations. While they may have small jobs such as shoe-shining or market-selling to pull through, many also end up dying on the pavement, victims of drugs, gang rivalry and disease (Cross \& Seagar., 2010).

Living on the street, with no supervision, protection or guidance, often makes street children vulnerable to a wide range of problems such as physical violence, community disapproval, police arrests, robberies of servings, lack of attachments, inability to cope and health related problems (Cross \& Seagar, 2010). Some of the hazards they face include sickness, physical injuries from motor accidents, street fights, harassment from extortionists and police, sexual exploitation by paedophiles and pimps, exposure to substance abuse and sexually transmitted diseases (Cross \& Seagar, 2010). Many of street children are denied to their access to the basic rights including education, healthcare and protection from child abuse and exploitation. On the streets, they frequently survive by scavenging, begging, steeling or working in informal sectors in low-paying jobs. Some exchange sex for money, thus increasing the risk of contracting HIV and other sexually transmitted diseases (Kissin et al., 2007). Street children represent a socially and economically disadvantaged population. Their medical care is poorly funded and in most resource-limited countries more than $80 \%$ of victims of trauma have no definable source of private or governmental health care insurance at the time of their injury (Amury \& Komba, 2010).

Physical violence (trauma) among street children is an emerging but neglected major public health problem in most developing countries and yet have a significant adverse effect on the country's economy and health services in terms of morbidity, mortality and long term disability among this patients (Nkomo \& Olufemi, 2001). In Tanzania, like many other low and middle income countries, the occurrence and health impact of trauma among street children has not received a great deal of attention mainly due to lack of data. Trauma among street children is an emerging silent epidemic in Mwanza City in north-western Tanzania and claims the lives of many of these children. This study was undertaken to determine the incidence, aetiological spectrum, injury characteristics and treatment outcome among street children admitted at Bugando Medical Centre in Mwanza, Tanzania.

\section{Materials and Methods}

\section{Study design and setting}

This was a descriptive prospective study involving street children aged below 18 years admitted for trauma at Bugando Medical Centre (BMC) from January 2008 to March 2014. BMC is one of the four largest tertiary care hospitals in the country and it is located in Mwanza City in the northwestern part of Tanzania. It has a bed capacity of 1,000 and serves as a referral centre for tertiary specialist care for a catchment population of approximately 13 million people from neighbouring 
regions. It is also a teaching hospital for the Catholic University of Health and Allied SciencesBugando (CUHAS-Bugando).

\section{Study population}

The study population included street children aged less than 18 years who presented to the Accident \& Emergency (A \& E) Department of BMC with history of trauma during the period of study. Patients who died before complete assessment were excluded from the study. Convenience sampling of patients who met the inclusion criteria was performed until the sample size was reached. Patients were screened for inclusion criteria and those who met the inclusion criteria were consecutively enrolled into the study.

All recruited patients were first resuscitated in the A\&E department according to Advanced Trauma Life Support (ATLS). From the A \& E department, patients were taken into the surgical or orthopaedic and trauma wards from where necessary investigations were completed and further treatment was instituted. Patients with severe injuries requiring ventilatory support were admitted in the intensive care unit (ICU). The severity of injury was determined using the Kampala Trauma Score II (KTS II) (Mutooro et al., 2010). KTS II is scored based on the following parameters (A) age in years (i.e. 5-55 $=1,<5$ and $>55=0$ ), (B) number of serious injuries (i.e. none $=2$, one injury $=1$ and $>$ one injury $=0$ ), (C) systolic blood pressure (i.e. $>89 \mathrm{mmHg}=2$, 89$50 \mathrm{mmHg}=1, \leq 49 \mathrm{mmHg}$ ), (D) respiratory rate (i.e. $0-29 / \mathrm{min}=2,>30 / \mathrm{min}=1$ and $\leq 29 / \mathrm{min}$ ) and neurologic status (i.e. alert $=3$, responds to verbal stimuli $=2$, responds to painful stimuli $=1$ and unresponsive $=0$ ) on presentation. Kampala Trauma Score total $=A+B+C+D+E$.

Severe injury consists of a KTS $\| \leq 6$, moderate injury $7-8$, and mild injury $9-10$. Patients with head injuries were classified according to Glasgow Coma Scale (GCS) into: severe (GCS 3-8), moderate (GCS 9-12) and mild (GCS 13-15). An initial systolic blood pressure (SBP) from each patient was also recorded on admission to assess the presence of shock.

Routine investigations including haematological (haemoglobin, blood grouping \& crossmatching), biochemical (serum creatinine and serum electrolytes) and imaging (plain x-rays of the chest / abdomen, pelvis, spines and limbs, abdominal ultrasound and CT scan) were performed on admission. Depending on the type of injury, patients were treated either conservatively or surgically.

\section{Data collection}

Data were collected using a pretested questionnaire. Included in the questionnaire were patient's characteristics (age, sex, education), circumstances of injury (timing of injury, place of injury, nature of injury, prehospital care, cause of injury, injury-arrival time and waiting time), injury characteristics (mechanism of injury, body region affected, type of injury, severity of injury), treatment offered, outcome variables were complications, length of hospital stay and mortality.

\section{Data analysis}

Data analysis was performed using Statistical Package for Social Sciences (SPSS) version 17.0 for Windows (SPSS, Chicago IL, U.S.A). The median (+ IQR) and ranges were calculated for continuous variables whereas proportions and frequency tables were used to summarize categorical variables. Chi-square $\left(\chi^{2}\right)$ test were used to test for the significance of association between the independent (predictor) variables (patient's characteristics (age, sex, education), circumstances of injury (timing of injury, place of injury, nature of injury, prehospital care, cause of injury, injury-arrival time and waiting time), injury characteristics (mechanism of injury, body region affected, type of injury, severity of injury), treatment offered) and dependent (outcome) variables (treatment complications, hospital stay and mortality) in the categorical variables. The level of significance was considered as $p$-value $<0.05$. Multivariate logistic regression analysis was 
used to determine predictor variables that predict the treatment complications, hospital stay and mortality.

\section{Ethical consideration}

Ethical approval to conduct the study was sought and obtained from the CUHAS-Bugando/BMC Joint Institutional Ethic Review Committee before the commencement of the study. However, in the current study, parents/guardians were not available, so children were asked personally to provide their assent to participate in the study. Individual written assent was obtained from each participant. Assent was obtained by a social worker trained in assenting vulnerable populations (especially children). Patient's refusal to provide assent or withdrawal from the study did not alter or jeopardize their access to medical care.

\section{Results}

During the period of study, a total of 2,963 paediatric trauma patients were admitted to the paediatric wards of BMC. Of these, $342(11.5 \%)$ were street children and these made the study population. Out of the 342 patients, 210 (61.4\%) were those who permanently live on the street without a family network (Type I), 92 (26.9\%) were those who live on the streets during the day but return to some form of family at night (Type II) and $40(11.7 \%)$ were those who work on the streets as their only means of getting money (Type III). The age of patients at presentation ranged from 4 to 18 years with a median of 12 years (+IQR of 10 to 14 years). The modal age group was 11-15 years accounting for $182(53.2 \%)$ patients. Type III Street children were found to be significantly older as compared to Type I and II street children ( $\mathrm{p}<0.001)$. Of the 342 patients, 298 $(87.1 \%)$ were males and $44(12.9 \%)$ were females with a male to female ratio of $6.8: 1$. This sex difference was statistically significant $(p=0.003)$.

The majority of patients, $220(64.3 \%)$ had no formal education and the remaining 122 (35.7\%) patients had primary education. Of the 122 patients who had primary education, only 34 (27.9\%) completed class seven and the remaining 88 (72.1\%) patients who had attended primary school education at some point stopped school even before they were street children. None of the patients were currently in school. Among the 342 street children, no patient had definable source of private or governmental health care insurance at the time of injury. Financial problem was the most common reason for leaving home accounting for 214 (62.6\%) patients (Table 1). More than three quarter of patients (street children) had lived and/ or worked on the street for more than one year. Boys were more likely to start living on the street at a younger age than girls (median age for the male $=12$ years versus 16 years for girls) and this was statistically significant ( $p$ $=0.011$.

Table 1: Reasons for leaving home among street children

\begin{tabular}{lll}
\hline Reasons for leaving home & Frequency & Percentages \\
\hline Financial problem & 214 & 62.6 \\
Conflict with parents & 102 & 29.8 \\
In search of job & 89 & 26.0 \\
Parent divorced & 76 & 22.2 \\
Parent deceased & 32 & $9 \cdot 3$ \\
Child abuse & 18 & 5.3 \\
Parent neglect & 15 & 4.4 \\
Maltreatment & 10 & 2.9 \\
Other reasons & 10 & 2.9 \\
No reason given & 42 & 12.3 \\
\hline
\end{tabular}


Most of injuries occurred during night hours in $70.2 \%$ of cases. More than three quarter of injuries occurred along the street. The vast majority of patients, $248(72.5 \%)$ were intentional. Assault was the most frequent cause of injury accounting for $73.7 \%$ of cases. This was followed by road traffic accidents (RTAs) in $62(18.1 \%)$ patients. Forty-two $(67.7 \%)$ of RTAs were related to motorcycle injuries affecting mainly pedestrian in $34(81.0 \%)$ cases. No patient in this study received prehospital care. The majority of patients, 202 (59.1\%) reported to the A \& E department late (i.e. more than 24 hours after injury) with only 140 (40.9\%) presenting within 24 hours of injury. Most of patients, 332 (97.1\%) were brought in by police and the remaining $10(2.9 \%)$ were brought in by Good Samaritan. No patient was brought in by ambulance. The median waiting time (i.e. time interval taken from reception at the $A \& E$ department and reception of treatment) ranged from 1 to 12 hours with a median of 6 hours (+ IQR of 2 to 8 hours). The majority of patients, $242(70.8 \%)$ received definitive treatment after six hours and more after injury (Table 2 ).

Table 2: Distribution of patients according to the circumstance of injury $(\mathrm{n}=342)$

\begin{tabular}{llll}
\hline Variable & Response & Frequency & Percentages \\
\hline Time of injury & Night & 240 & 70.2 \\
Place of injury & Day & 102 & 29.8 \\
& Along street & 264 & 77.2 \\
& Recreational & 34 & 9.9 \\
& Working place & 20 & 5.8 \\
& Home & 16 & 4.7 \\
Nature of injury & Unknown & 8 & 2.3 \\
& Intentional & 248 & 72.5 \\
Cause of injury & Unintentional & 84 & 24.6 \\
& Indeterminate & 10 & 2.9 \\
& Assault & 252 & 73.7 \\
& Road traffic accidents & 62 & 18.1 \\
& Falls & 8 & 2.3 \\
Pre-hospital care & Sport related & 5 & 1.5 \\
Injury-arrival time & Burns & 5 & 1.5 \\
Waiting time & Others & 10 & 2.9 \\
& Done & 0 & 0 \\
& Not done & 342 & 100 \\
& $<24$ hours & 140 & 40.9 \\
& $\geq 24$ hours & 202 & 59.1 \\
& $<6$ hours & 100 & 29.2 \\
& $\geq 6$ hours & 242 & 70.8 \\
\hline
\end{tabular}

Blunt objects including stones, iron bars, sticks, bottles and sharp objects such as machetes, knives, axes, screw drivers were the most common weapons through which violence was inflicted accounting for 140 (40.9\%) of cases. Fists, slaps and kicks were used to inflict violence in $104(38.2 \%)$ of cases. The use of guns to inflict violence was recorded in $8(2.3 \%)$ of cases. Blunt injuries were the most common mechanism of injuries in 260 (76.0\%) patients followed by either penetrating injuries (cut wounds, stabbing and gunshot) or both in $68(19.9 \%)$ patients. Spilling with hot liquids or chemical was the mechanism of injury in $5(1.6 \%)$ of victims. Other mechanism of injury such as foreign body insertion and others were documented in 14 (4.1\%) patients. Musculoskeletal (mainly lower limbs) and head were the most common body regions affected in $30.8 \%$ and $25.3 \%$ of cases, respectively (Figure 1 ).

Soft tissue injuries (wounds) were the most common type of injuries affecting 322 (94.2\%) cases (Table 3). According to Kampala Trauma Score II (KTS II), the majority of patients sustained moderate trauma (KTS II = 7-8) in $186(54.4 \%)$ patients. Severe trauma (KTS II $\leq 6)$ and mild trauma (KTS II $=9-10)$ were recorded in $98(28.7 \%)$ and $58(16.9 \%)$ patients respectively. Two hundred and 
forty-eight (72.5\%) patients had isolated injuries and the remaining 94 (27.5\%) had multiple injuries. Out of 92 head injury patients, 49 (53.3\%) patients had moderate head injury, 24 (26.1\%) and 19 (20.7\%) patients had severe and mild head injuries respectively.

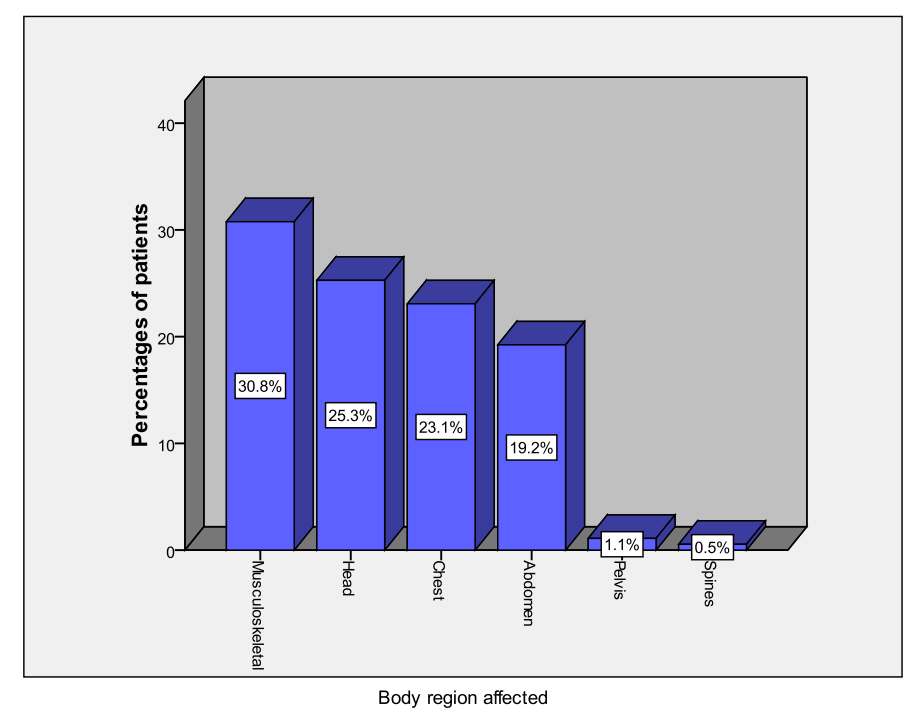

Figure 1: Distribution of patients according to the body region affected

Table 3: Distribution of patients according to the type of injury

\begin{tabular}{lll}
\hline Type of injury & Frequency & Percentages \\
\hline Soft tissue injuries (wounds) & 322 & 94.2 \\
Fractures /dislocations & 34 & 9.9 \\
Visceral injuries & 30 & 8.8 \\
Haemothorax & 24 & 7.0 \\
Cranio-cerebral injury & 18 & 5.3 \\
Pneumothorax & 12 & 3.5 \\
Burns & 5 & 1.6 \\
Other injuries & 14 & 4.1 \\
\hline
\end{tabular}

Twelve (3.5\%) patients were treated conservatively with simple wound dressing, broad spectrum antibiotics, tetanus prophylaxis and analgesics and discharged. The remaining 330 (96.5\%) patients were admitted and underwent definitive surgical treatment of which wound debridement was the most common surgical procedure performed in $322(97.6 \%)$ of cases.

Table 4: Distribution of patients according to the type of surgical procedure performed $(\mathrm{N}=330)$

\begin{tabular}{lll}
\hline Type of surgical procedure & Frequency & Percentages \\
\hline Wound debridement & 322 & 97.6 \\
Tube thoracostomy & 36 & 10.9 \\
Treatment of fractures/dislocations & 34 & 10.3 \\
Exploratory laparotomy & 30 & 9.1 \\
Skin grafting / flaps & 12 & 3.6 \\
Craniotomy/ burr holes & 5 & 1.5 \\
Colostomy & 3 & 0.9 \\
Other surgical procedures & 14 & 4.2 \\
\hline
\end{tabular}

Sixty-eight (39.4\%) patients developed 80 complications of which surgical site infection was the most common complication accounting for $70.0 \%$ of cases (Figure 2 ). 


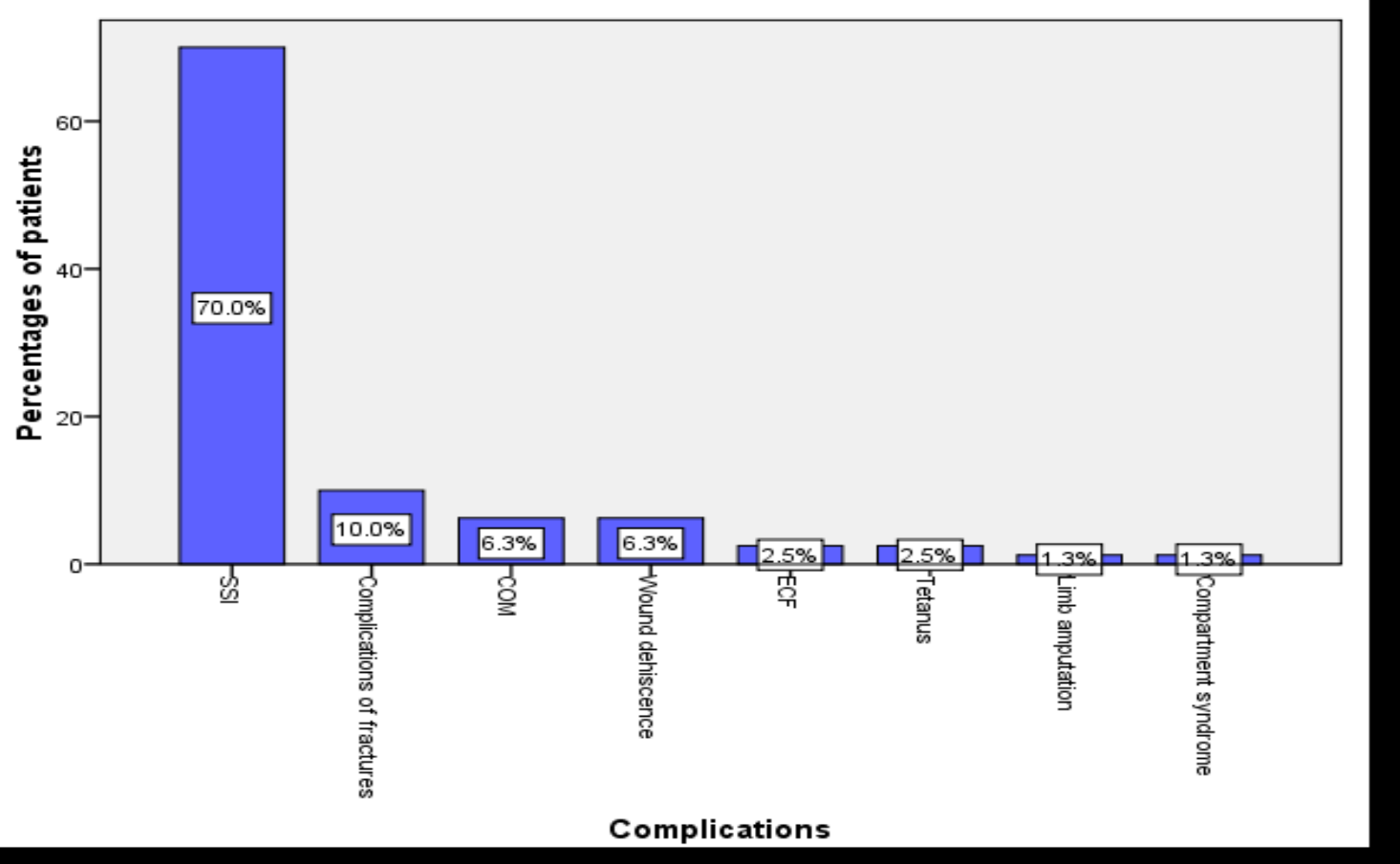

Figure 2: Distribution of patients according to complications

Key: $\mathrm{SSI}=$ Surgical site infection, $\mathrm{COM}=$ Chronic osteomyelitis, $\mathrm{ECF}$ = Enterocutaneous fistula

The overall length of hospital stay (LOS) ranged from 1 to 72 days with a median of 6 days (+IQR of 2 to 8 days). The LOS for non-survivors ranged from 1 day to 16 days with a mean of 2 days (+IQR of 1 to 3 days). Patients who had long bone fractures, burns and those who developed complications had prolonged LOS and according to multivariate logistic regression analysis this was statistically significant $(p<0.001)$.

In this study, 46 patients died giving a mortality rate of $13.5 \%$. According to multivariate logistic regression analysis; injury-arrival time $(\mathrm{OR}=2.4,95 \% \mathrm{Cl}(1.3-5.6), \mathrm{p}=0.002)$, severe injury $(\mathrm{KTS}<6)(\mathrm{OR}=3.6,95 \% \mathrm{Cl}(2.5-7.9), \mathrm{p}=0.001)$, severe head injuries $(\mathrm{OR}=5.1,95 \% \mathrm{Cl}(4.6-8.2), \mathrm{p}$ $=0.012)$ and surgical site infection $(\mathrm{OR}=2.9,1.1-7.9), \mathrm{p}=0.023)$ were the main predictors of mortality.

\section{Discussion}

Trauma among street children is an increasing public health problem in Mwanza city and its incidence is increasing at an alarming rate (Simon et al., 2013). In this study, the incidence of trauma among street children was found to be higher than that reported by Ayaya \& Esamai (2001) in Kenya and Thapa et al. (2009) in Nepal. This difference in the incidence of trauma among street children reflects differences, between countries, in the vulnerability to trauma among these patients.

The home-based street children (Type II) in this study was reported in about a quarter of cases which is in agreement with a study in South Africa (Cross \& Seagar, 2010), but at variant with reports in developed countries where home-based street children are reported to be $75-90 \%$ of cases (Benitez, 2011). In comparison with home-based street children, street-based street children (Type I) are more likely to engage in illegal activities such as shoplifting, stealing, and selling drugs (Nkomo \& Olufemi, 2001). Low incidence of Type III -street children in this study can be explained by the fact that Type III-street children were found to be older as compared to Type I and II street children and therefore they were less vulnerable to trauma. Type III-street children 
were commonly engaged in activities such as selling foods, fruit or sweets, washing cars or involved in illicit activities such as drug dealing and commercial sex work (data not shown).

Our patients in this study were found to be younger than that reported in other studies (Cross \& Seagar, 2010) reflecting that young street children are more vulnerable to trauma resulting from physical violence, road traffic accidents, street fights, harassment from extortionists and police and assaults as compared to older ones. Also, high incidence of trauma in this age group reflects lack of coordination and unawareness of dangerous substances. In addition, living on the street, with no supervision, protection or guidance makes young street children more vulnerable to trauma than older ones. On the other hand, in the present study, males were seven times more than females. This male predominance concurs with other studies (Aptekar, 1994; Mufune, 2000; Sorsa et al., 2002). The reasons for the male preponderance in our study may be attributed to the overactive nature of male street children as compared to the females. In keeping with an unpublished report in Mbeya municipality (2002), findings from study have indicated that boys are likely to start living on the streets at a young age than girls. This observation may be attributed to prevailing gender roles in many ethnic groups in Tanzania. Whilst girls are commonly socialized for reproductive role (Cross \& Seagar, 2010; Kok et al., 2010) and obliged to engage in household chores their male counterparts are frequently socialized to engage in remunerative productive roles, then allowed to go to street to look for money earlier than girls (Kok et al, 2010).

With respect to educational attainment, only about a quarter of the street children had completed primary school education and about three quarters had dropped out of school. This observation is consistent with a study done by Mkombozi Centre (2005) in Kilimanjaro, Tanzania which found that many children living in the streets were school drop outs. Many parents/guardians are too poor to provide school requirements for children such as uniforms and books. As a result, many children drop out of schools and find their way to the streets.

As reported in other studies (Mufune, 2000; Sorsa et al., 2002), assault was the most frequent cause of injury in this study. This is at variant with other studies in general population where road traffic accident is commonly reported as the most common cause of injury. This was followed by road traffic accidents of which more than two third of injuries were related to motorcycle accidents affecting mainly pedestrian in more than eighty percent of cases. High incidence of pedestrian injuries among street children has been attributed to their underdeveloped abilities to dealing with traffic situations, both cognitive (attention focus, interpreting signs) and perceptual (locating sounds, judging speed, peripheral vision) (Densmore et al., 2006).

The prehospital care of injured paediatric patients is the most important factor in determining the ultimate outcome after injury (Monini et al., 2000). In the present study, none of the patients had received any pre-hospital care at the site of injury and majority of them were brought in by police and Good Samaritan who are not trained to care for trauma patients. The lack of pre-hospital care in low and middle income countries like Tanzania and ineffective ambulance system for transportation of patients to hospitals are a major challenge in providing care for paediatric injury patients (Simon et al., 2013). The challenge is even more conspicuous among street children due to their poor access to the basic rights including healthcare and protection from child abuse and injuries.

In the current study, more than half of street children presented late to the A \& E department, which is contrary to the previous study done by Simon et al. (2013) who reported that the majority of paediatric injury patients presented to the A \& E department within 24 hours of injury. The delay in presentation to hospital in our patients reflects low utilization of health care as a result of poor accessibility, availability, affordability and acceptability to health care facility. Waiting time in emergency departments may be attributable to many factors and may stretch up to three hours before completion of all necessary procedures, even in developed 
countries (Havili et al., 1996; Lambe et al., 2003). This study found that more than two thirds of the patients received definitive treatment after six hours and more of arrival at the $A \& E$ Department. We could not establish the reasons for the prolonged waiting time in this study.

In agreement with previous studies (Osmond et al., 2002; Simon et al., 2013), the present study found that the musculoskeletal and head were the most common body regions affected and the later accounted for most of the deaths. The high figure of musculoskeletal injuries affecting mainly the lower limbs is attributable to the large number of pedestrians. Pedestrians are unprotected road users and therefore they are highly exposed to high risk of limb injuries (Osmond et al., 2002). The type of injuries in this study is comparable with what is reported in other studies (Osmond et al., 2002; Simon et al., 2013).

Most of our patients were treated surgically, which is in agreement with other similar studies (Osmond et al., 2002; Simon et al., 2013). The high incidence of surgical treatment in our study is attributable to the high incidence of injuries that required surgical intervention. In this study, wound debridement was the most frequent surgical procedure performed. The pattern of complications in the present study is similar to what was reported by Simon et al (2013) at the same centre. Early recognition and management of complications following trauma among street children is of paramount in reducing the morbidity and mortality resulting from this form of trauma. Prolonged duration of hospital stay is associated with unacceptable burden on hospital resources as well as on increased costs of health care (Kang et al., 2000; Muller et al., 2001; Simon et al., 2013). In the present study, patients who had long bone fractures, burns and those who developed complications had prolonged duration of hospital stay.

The current study had a mortality rate higher than that reported by Simon et al. (2013) in the same setting. Factors responsible for high mortality in our study included injury-arrival time, severe injury, severe head injuries and surgical site infection. Addressing these factors responsible for high mortality in our patients is mandatory to be able to reduce mortality associated with these injuries.

In conclusion, trauma among street children is an emerging but neglected epidemic in our environment and contributes significantly to unacceptably high morbidity and mortality. Assault was the most frequent cause of injury. Urgent preventive measures targeting at reducing the occurrence of assault is necessary to reduce the incidence of trauma among street children in this region.

\section{Acknowledgements}

The authors would like to thank the members of staff of department of Surgery for their invaluable contributions in the preparation of this manuscript.

\section{References}

Amury, Z. \& Komba, A. (2010) Coping strategies used by street children in the event of Illness. Research on Poverty Alleviation, Research Report 10/7.

Aptekar, L. (1994) Street Children in the Developing World: A review of their condition. Cross Cultural Research 28, $195-224$

Benitez, T.S. (2011) State of the World's Street Children: Research. Consortium for Street Children, Street Children Series 2

Cross, C. \& Seagar, J. (2010) Towards identifying the causes of South Africa's street homelessness: Some policy recommendations. Development Southern Africa 27, 143-158

Densmore, J.C., Lim, H.J., Oldham, K.T. \& Guice, K.S. (2006) Outcomes and delivery of care in pediatric injury. Journal of Pediatric Surgery 41, 92-98. 
Ensign, J. \& Gittelsohn, J. (1998) Health and access to care: perspectives of homeless youth in Baltimore City, U.S.A. Social Science \& Medicine 47, 2087-2099

Havili, J.H., van Alphen, S., Fairweather, S. \& Van derpyl, M. (1996) Waiting in the emergency department. New Zealand Medical Journal 109, 159-161.

Kang, E.G., Sharma, G.K. \& Lazano, R. (2000) The global burden of injuries. American Journal of Public Health 90, 523-526.

Kissin, D.M., Zapata, L., Yorick, R., Vinogradova, E.N., Volkova, G.V. Cherkassova, E., Lynch, A., Leigh, A.J., Jamieson, D.J., Marchbanks, P.A. \& Hillis, S. (2007) HIV seroprevalence in street youth, St Petersburg, Russia. AIDS 21, 2333-2340

Kok, P., Cross, C. \& Roux, N. (2010) Towards a demographic profile of the street homeless in South Africa. Development Southern Africa 27, 21-37.

Kopoka, P.E. (2000) The Problem of Street Children in Africa: An ignored Tragedy. Paper presented at the international conference on Street Children's Health in East Africa, Dares-salaam, Tanzania, April 19 - 21. Unpublished.

Lambe, S., Washington, D.R., Finki, A., Laouri, M., Lin, H., Scuralfose, J., Brook, R.H. \& Asch, S.M. (2003) Waiting time in California's emergency departments. Annals of Emergency Medicine $41,35-44$.

Lugalla, J., \& Mbwambo, J. (1999) Street children and street life in urban Tanzania: The Culture of Surviving and its implications for children's health. International Journal of Urban and Regional Research 23, 329-344.

Mkombozi Centre (2005) Demonstrating the potential of MEMKWA to respond to the learning needs of street children. Accessed at: http://www.mkombozi.org/pdf/200511memkwa.pdf

Monini, M., Rezaishiraz, H. \& Zafarghandi, M.R. (2000) Characteristics and outcome of injured patients treated in urban trauma centers in Iran. Journal of Trauma 48, 503-507.

Mufune, P. (2000) Street Youth in Southern Africa. International Social Science Journal 5, 233-243.

Muller, M.J., Pegg, S.P. \& Rule, M.R. (2001) Determinants of death following burn injury. British Journal of Surgery $88,583-587$

Mutooro, S.M., Mutakooha, E. \& Kyamanywa, P. (2010) A comparison of Kampala trauma score II with the new injury severity score in Mbarara University Teaching Hospital in Uganda. East and Central African Journal of Surgery 15, 62-70.

Nkomo, M. \& Olufemi, O. (2001) Educating street and homeless children in South Africa: the challenge of policy implementation. International Journal of Education Policy, Research and Practice 2, 337-356.

Omiyinka, F.O. \& Festus, F.A. (2010) Social networks and livelihood of street children in Ibadan, Nigeria. Journal of International Social Research 3, 10

Osmond, M.H., Brennan-Barnes, M. \& Shephard, A.L. (2002) A 4-year review of severe pediatric trauma in eastern Ontario: a descriptive analysis. Journal of Trauma 52, 8-12

Simon, R., Gilyoma, J.M., Dass, R.M., Mchembe M.D. \& Chalya, P.L. (2013) Paediatric injuries at Bugando Medical Centre in northwestern Tanzania: a prospective review of 150 cases. Journal of Trauma Management \& Outcomes 7, 10.

Sorsa, S., Kidanemariam, T. \& Erosie, L. (2002) Health problems of street children and women in Awassa, Southern Ethiopia. Ethiopian Journal of Health Development 16, 129-137

Thapa, K., Ghatane, S. \& Rimal, S.P. (2009) Health Problems of street children of Dharan municipality. Kathmandu University Medical Journal 7, 272-279

UNICEF (2012) The State of the World's Children: Children in an Urban World. www.unicef.org//sowc2012>.perspectives

WHO (2010) United Nations, World Urbanization Prospects. The 2009 revision. Department of Economic and Social Affairs, Population Division, United Nations, New York, 2010; World Health Organization and United Nations Human Settlements Programme, Hidden Cities: Unmasking and overcoming health inequities in urban settings. 